\title{
Practical Application of Aesthetic Characteristics in Landscape Design of Mountainous Residential District
}

\author{
Yi $\mathrm{Li}^{1 *}$, Duwen Shen ${ }^{1}$ and Ran Zhang ${ }^{1}$ \\ ${ }^{1}$ Architectural and Urban Planning Department, Chongqing College of Architecture and Technology, 401331, China
}

\begin{abstract}
In the process of landscape planning and design of a mountainous residential area, planners make full use of a variety of aesthetic features, create their own characteristics, create community landscape leading the needs of modern urban life, and provide reference for improving the quality of mountain residential area.
\end{abstract}

\section{Background}

China's mountainous areas account for about $2 / 3$ of the country's land area, and at least $50 \%$ of the country's urban terrain is mountainous [1]. According to the code for vertical planning of urban and rural construction land [2], in the selection and layout of urban and rural construction land, the natural slope and planning slope of residential land should be less than $25 \%$. The fluctuating terrain of Mountainous Residential Area Planning increases the difficulty of building layout and road organization, but it also provides conditions for building skyline with unique style and artistry and providing original and unique three-dimensional activity space. At the same time, combined with the actual situation, it can also create a land-saving and affordable public service facilities supporting [3].

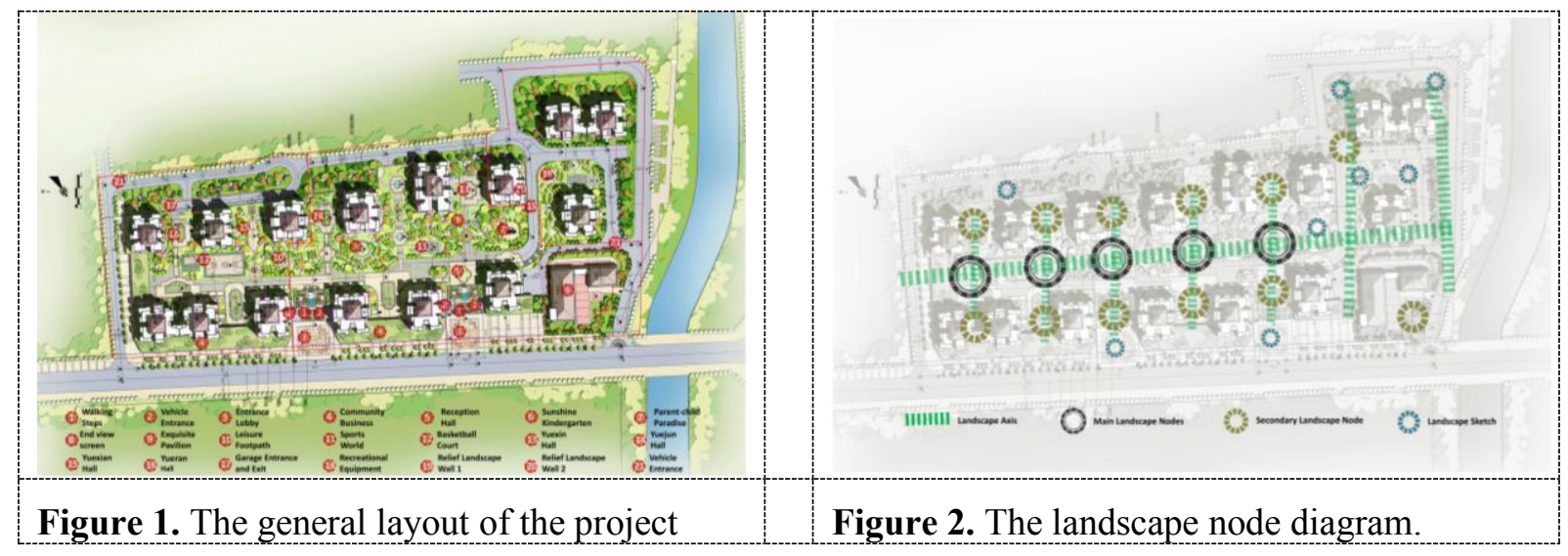

In the process of landscape planning of a typical mountainous residential area in Chongqing, planners make full use of the aesthetic features of landscape, combine with the requirements of low impact development, respect the mountainous terrain and landforms, make rational use of the terrain and geological conditions, and develop a characteristic and practical residential landscape space in Mountainous Areas, comprehensively improve the living quality, create interactive communities, and increase private communication space.

\section{Aesthetic Characteristics Construction of Slope Landscape} and

\subsection{Unity and diversity}

In the process of slope landscape planning, various forms of elements should be organically combined and integrated to achieve coordination and unity, so as to form a colorful and ever-changing harmonious beauty and realize unity and diversity [4].

\footnotetext{
*Corresponding author's e-mail: cqfdc2008@163.com
} 

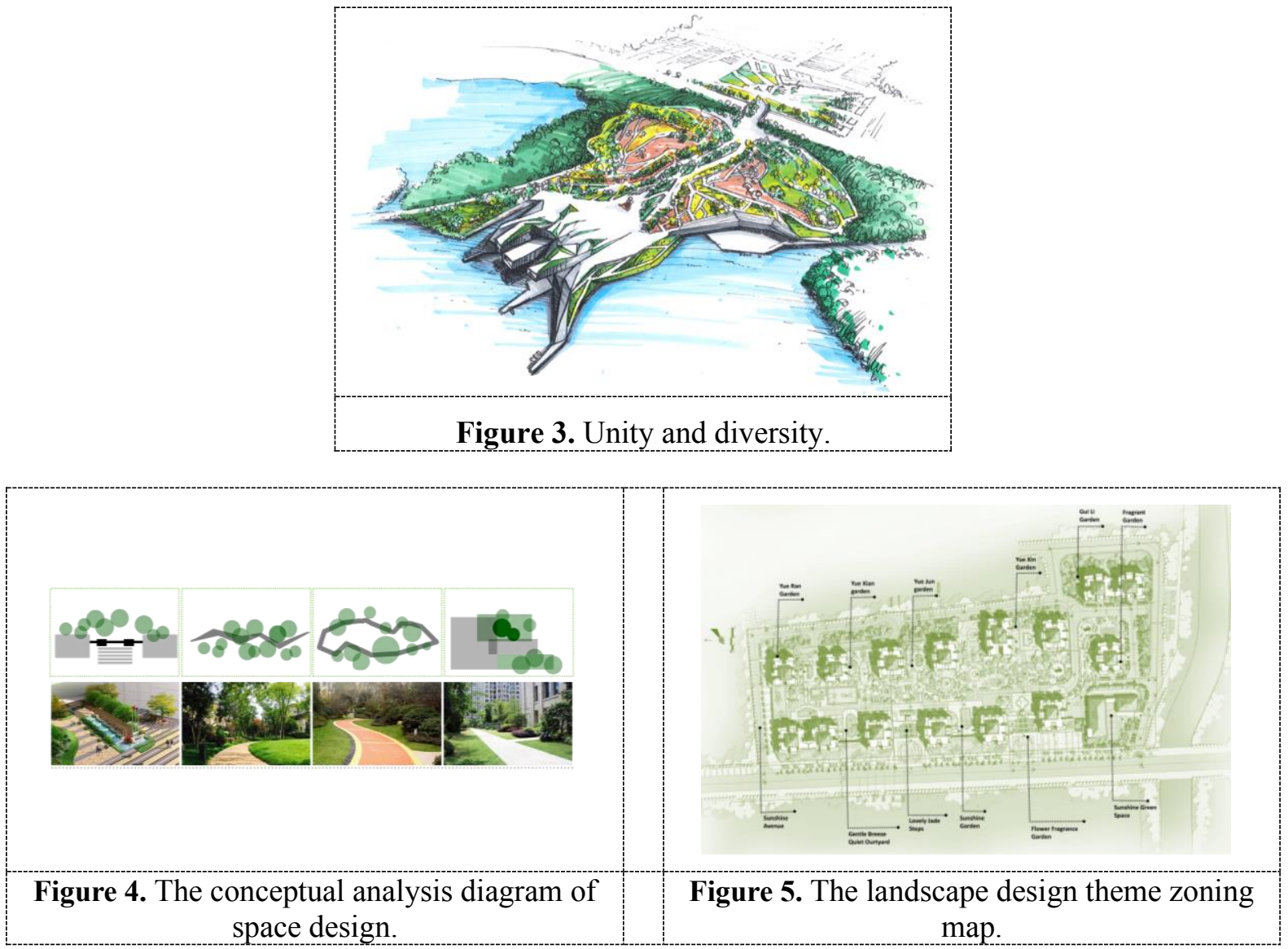

In the sunshine rose city slope landscape space combination, the designer combines the function to create the suitable landscape. The entrance and exit landscape of the community is simple and fresh, the footpath connects with the square to enter the house, and the residents have a strong sense of belonging. Part of the private local landscape, through the subtle approach, give people rich association. The pan lobby landscape extends the landscape and makes the home full of green. The promenade connects with the residential space to increase the space continuity and residents' interaction, forming a dynamic network. Through a variety of spatial combination, landscape elements collocation, to achieve diversity and unity, so that residents fully integrated into nature, and harmonious coexistence with nature.
The slope landscape axis is not obvious, the terrain is changeable, and the local use of symmetrical techniques can achieve the design effect of "small to see big" and "surprise". At the same time, combined with the landscape elements shape, color, material, virtual and real form a contrast, to achieve a variety of unified artistic effect.

At the entrance and exit of the project, planners use this aesthetic feature. Taking the slope flower pool as the axis, plant configuration and hard pavement, green leaf plants and color plants match, sign entity and hollow out to achieve the contrast effect. The use of contrast and symmetry, slope and entrance integration, give a clean, neat, comfortable image, enhance the charm of the community.

\subsection{Contrast and symmetry}

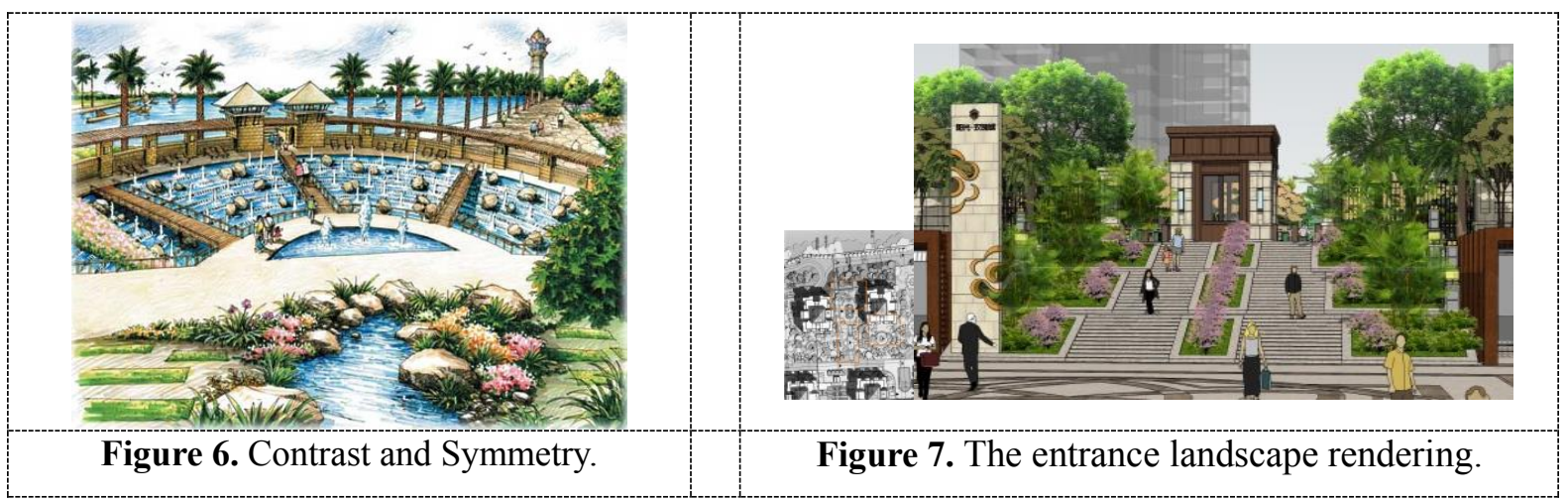




\subsection{Rhythm and cadence}

In the slope landscape planning, we should follow the aesthetic feeling rules of rhythm and cadence, and make full use of the elements of spatial form, color, material, terrain and topography [4], and grasp the cadence in combination with the actual environment, so as to give people a sense of visual comfort.

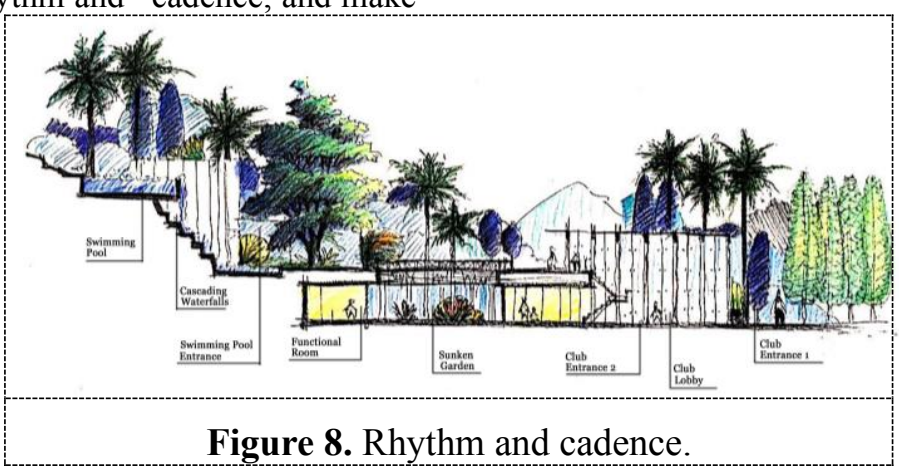

In the residential area planning, in order to improve the visual space and quality of life, realize the landscape uniqueness and living comfort, we use rhythm and rhythm to create a landscape belt and create an interactive landscape effect. It enriches the landscape pattern and provides residents with a unique landscape perspective.

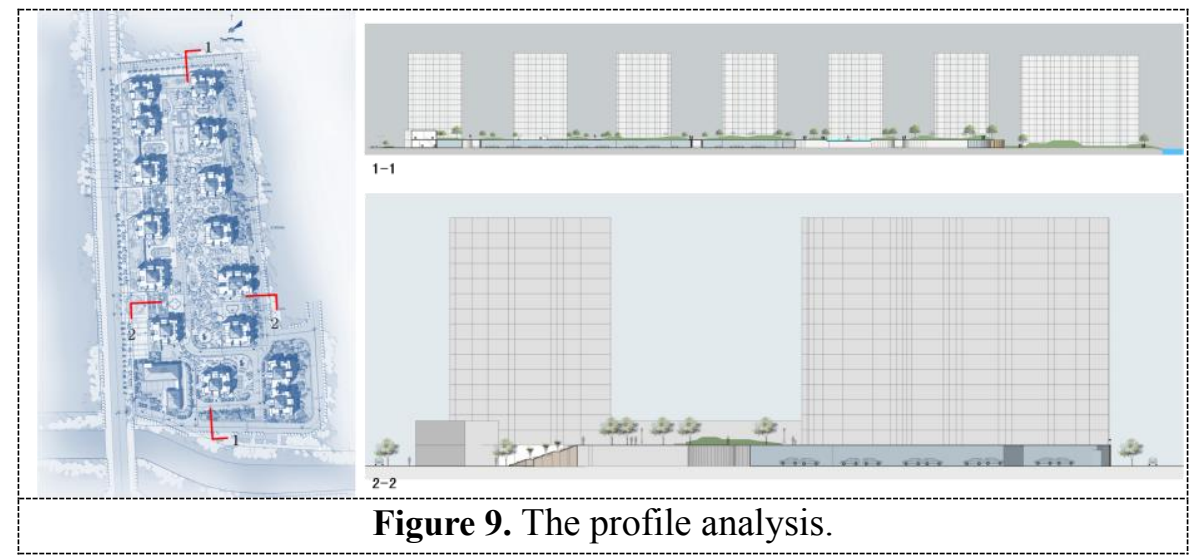

\subsection{Texture and proportion}

The proportion and texture can improve the vitality of the landscape and endow the slope landscape with more vitality. Through the same material texture beauty and concave convex feeling, the contrast expression of different materials and the fusion of similar materials. Then, the coordination between the whole and the part, between the parts or the whole is fully combined to achieve the aesthetic effect.

The planner of this project adopts the simple, lively, modern and generous European style in the facade of residential buildings, and uses glass, real stone paint, stone and other materials, vertical and horizontal changes in details and full of modern vertical lines to integrate the building into the landscape. Green space and hardbound place, public space and private space are fully combined, interpenetrated and integrated.

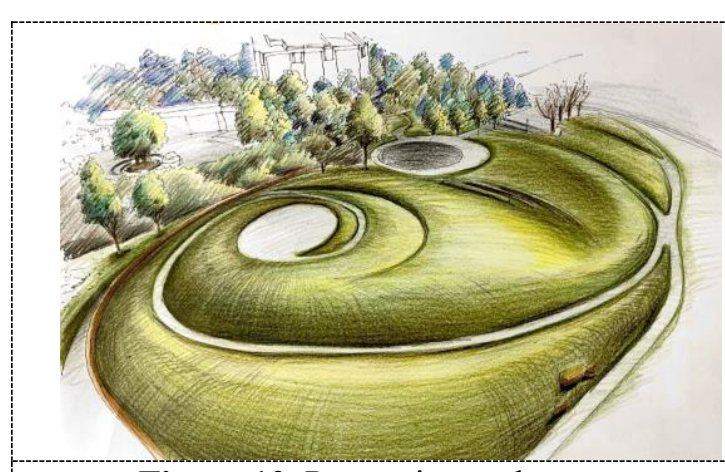

Figure 10. Proportion and texture.

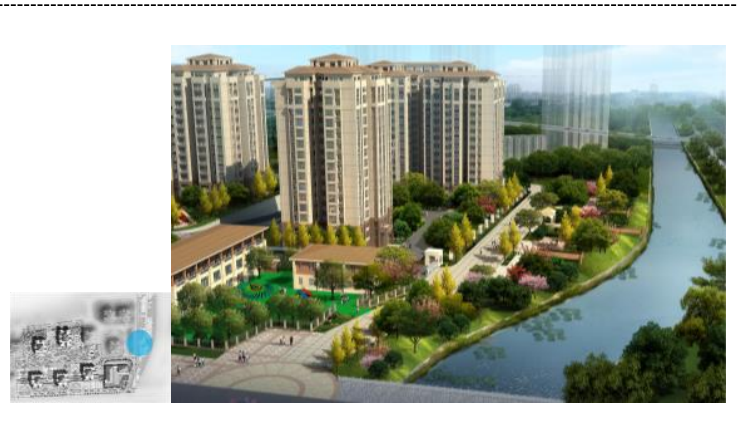

Figure 11. The waterfront landscape rendering. 


\section{Conclusion}

In the process of landscape planning and design of a hillside residential area in Chongqing, planners make full use of the aesthetic characteristics of rhythm, symmetry, texture ratio, diversity and unity to create their own characteristics and create a safe, comfortable, unique and livable modern community landscape, which provides theoretical and practical basis for landscape planning and design of Mountainous Residential Areas in the future, and how to improve the living quality of mountainous areas Reference is provided.

\section{References}

1. Li Yi. etc. (2019) Beauty of Slope Land: Practical Study on Slope Landscape Design. J. IOP Conference Series Earth and Environmental Science, 310:1-7.

2. Ministry of Housing and Urban-Rural Construction of the People's Republic of China. (2016) Code for Vertical Planning of Urban-Rural Construction Land. China Construction Industry Press. Beijing.

3. Li Gaoxiang. (2017) Strategy And Implementation Of Montanic Residential District Planning And Design. J. Planners(Supplement):44-48.

4. Yang Chengzhu. (2016) Design Research of Landscape Steps. D. Master's Thesis of Southeast University. 